\title{
UHRF1 is a Potential Molecular Marker for Diagnosis and Prognosis of Bladder Cancer
}

\author{
Motoko Unoki \\ Division of Epigenomics, Department of Molecular Genetics, \\ Medical Institute of Molecular Genetics, Kyushu University, \\ Japan
}

\section{Introduction}

Bladder cancer is the second most common cancer of the urinary system. An estimated 386,300 new cases and 150,200 deaths from bladder cancer occurred in 2008 worldwide (Jemal et al., 2011). The highest rates of bladder cancer incidence are found in industrially developed countries, particularly in North America and Western Europe (Parkin et al., 2005). Bladder cancer is more common in males. The cancer is the 7th most common cancer in males worldwide and 4th most common cancer in males in industrially developed countries, while the cancer is not ranked in the top 10 most common cancers in females even in industrially developed countries (Jemal et al., 2011). In industrially developed countries, approximately $90 \%$ of the cancers are transitional cell carcinomas (TCCs), while the remaining $10 \%$ are squamous cell carcinomas and adenocarcinomas (Stein et al., 2001).

There are several potential biomarkers for diagnosis and prognosis for bladder cancer, including Nuclear matrix protein-22 (NMP-22), human complement factor $\mathrm{H}$ related protein, telomerase, fibrin degradation product, and hyaluronic acid (Dey, 2004). Among these, only two biomarkers, NMP-22 and human complement factor $\mathrm{H}$ related protein, are in clinical use in Japan. Although these two markers are in clinical use, sensitivity and specificity of these markers are not perfect (van Rhijn et al., 2005); NMP-22 staining shows false positivity reactions in patients with hematuria, and the BTA (bladder tumour antigen) stat/BTA TRAK assay, which detects human complement factor $\mathrm{H}$ related protein, shows false positivity reactions in patients with urinary tract inflammation, recent genitourinary tumours and in cases of bladder stone (Dey, 2004). Cytology is still the most accurate diagnosis method, although sensitivity is not enough high (van Rhijn et al., 2005). Thus, discovery of a novel biomarker, which is sensitive and specific for bladder cancer, is an urgent subject.

\section{UHRF1 is a potential molecular marker for diagnosis and prognosis of bladder cancer}

UHRF1 (ubiquitin-like with PHD and ring finger domains 1), also known as ICBP90 (Inverted CCAAT box-binding protein of $90 \mathrm{kDa}$ ), was identified as a protein, whose expression is only detectable in proliferating cells, not in quiescent cells (Hopfner et al., 2000; Unoki et al., 2004). UHRF1 plays a central role in transferring DNA methylation status 
from mother cells to daughter cells. Its SET and RING finger-associated (SRA) domain recognizes hemi-methylated DNA that appears in newly synthesized daughter DNA strands during duplication of DNA strands through the $S$ phase (Arita et al., 2008; Avvakumov et al., 2008; Hashimoto et al., 2008). UHRF1 recruits DNA methyltransferase 1 (DNMT1) to the site with proliferating cell nuclear antigen (PCNA) and methylates the newly synthesized strands (Achour et al., 2008; Sharif et al., 2007). UHRF1 also recognizes tri/di-methylated $\mathrm{H} 3 \mathrm{~K} 9$, and recruits the H3K9 methyltransferase G9a, the histone deacetylase 1 (HDAC1), and the histone acetylase Tip60 (Achour et al., 2009; Hashimoto et al., 2009; Karagianni et al., 2008; Kim et al., 2009; Unoki et al., 2004), indicating that UHRF1 links DNA methylation and histone modification status (Fig. 1).

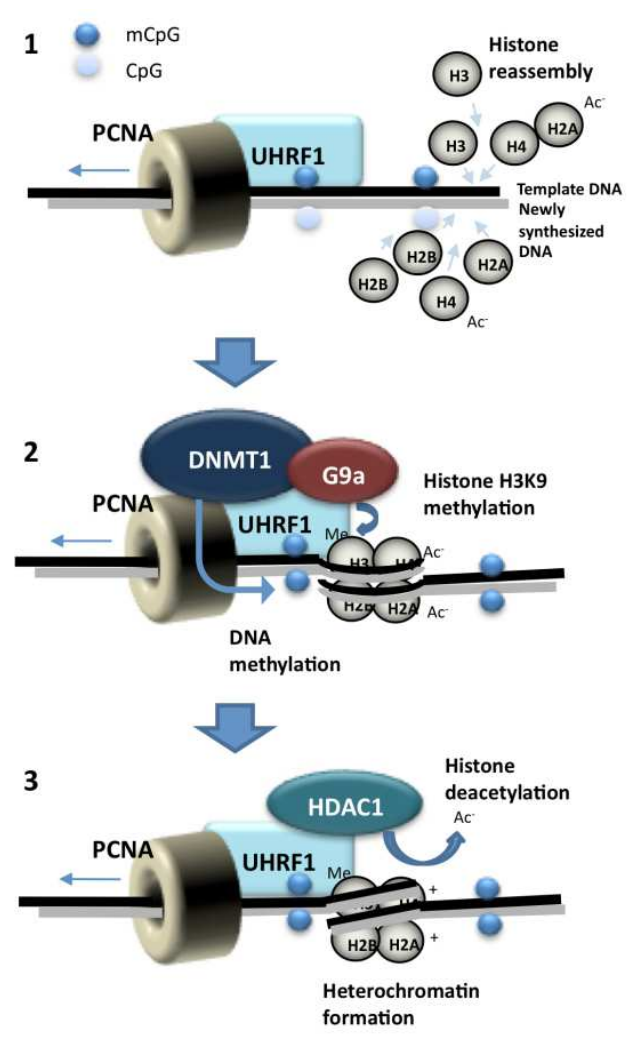

Fig. 1. Proposed mechanism of heterochromatin formation through UHRF1 at DNA replication fork or DNA repair site. 1) UHRF1 binds to PCNA and the SRA domain of UHRF1 recognizes hemi-methylated CPG on newly synthesized DNA. Then histones are reassembled. 2) UHRF1 recruits DNMT1 to methylate both DNA strands to transfer methylation status. UHRF1 also recruits G9a to methylate histone H3K9. Methylated histone H3K9 interacts with the Tudor-PHD domain of UHRF1. 3) UHRF1 recruits HDAC1 to the site and deacetylates histones. Then, histones become charged positively and bind to negatively charged DNA tightly, causing heterochromatin formation. This figure is cited from our article (Unoki et al., 2009a). 
UHRF1 promotes G1/S transition (Arima et al., 2004; Jeanblanc et al., 2005) and is a direct target of E2F transcription factor 1 (E2F1) (Abbady et al., 2005; Mousli et al., 2003; Unoki et al., 2004). The tumour suppressor p53, which is deficient in $50 \%$ of all human cancers (Hussain \& Harris, 2000), indirectly down-regulates UHRF1 through up-regulation of p21/WAF1 and subsequent deactivation of E2F1 (Arima et al., 2004) (Fig. 2).
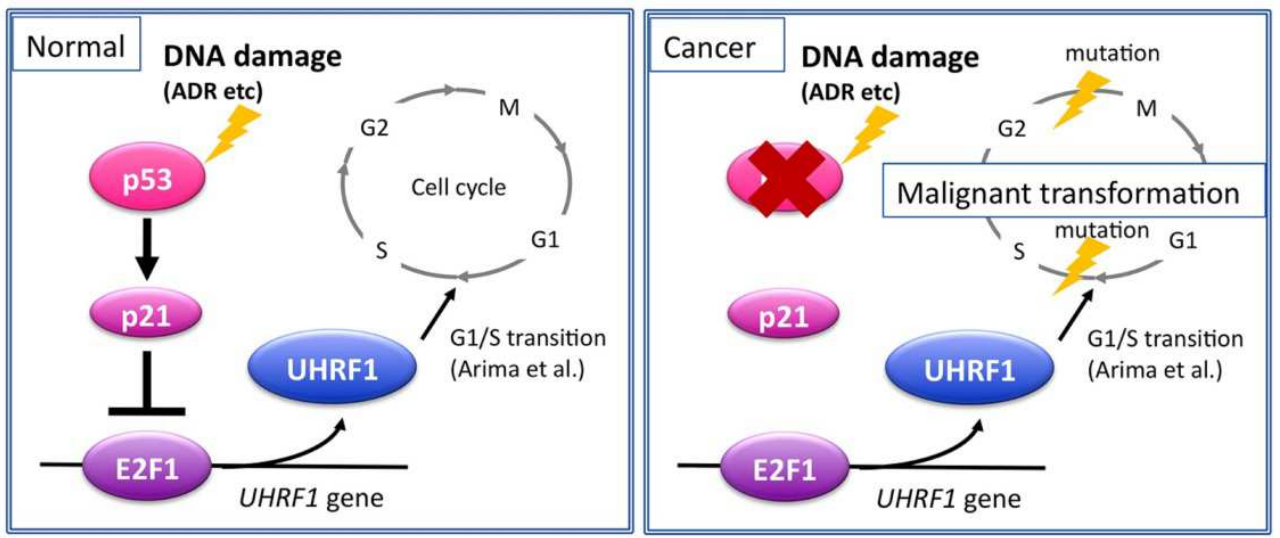

Fig. 2. Proposed p53-UHRF1 pathway model.

Expression of UHRF1 is up-regulated in various cancers, including breast cancer (Fig. 3), lung cancer (Fig. 4), prostate cancer, astrocytoma, pancreatic cancer, cervical cancer, and poorly differentiated thyroid carcinoma (Crnogorac-Jurcevic et al., 2005; Jenkins et al., 2005; Lorenzato et al., 2005; Mousli et al., 2003; Oba-Shinjo et al., 2005; Pita et al., 2009; Unoki et al., 2010; Unoki et al., 2004). Overexpression of UHRF1 in these cancers could be partially due to the inactivation of p53, although there could be several pathways, which regulate expression of UHRF1. Knock down of UHRF1 expression in cancer cells suppressed cell growth, indicating that UHRF1 is essential for progression of cancers and thus could be an anticancer drug target (Tien et al., 2011; Unoki, 2011; Unoki et al., 2009a; Unoki et al., 2004; Yan et al., 2011). Moreover, knockdown or inactivation of UHRF1 is reported to enhance sensitivity against current chemotherapies and radiation therapy in vitro (Alhosin et al., 2010; Jenkins et al., 2005; Jin et al., 2010; Li, X. et al., 2011; Li, X. L. et al., 2009; Muto et al., 2002). Therefore, UHRF1 is also an attractive target of cancer combination therapies (Bronner et al., 2007; Unoki, 2011; Unoki et al., 2009a).

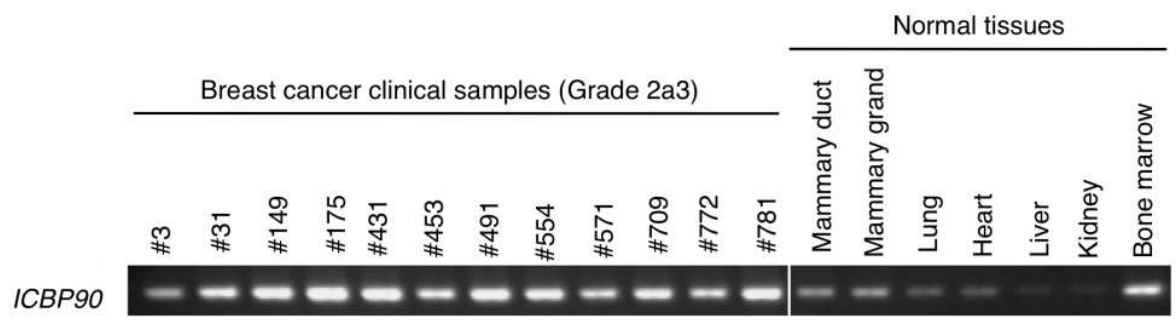

Fig. 3. Expression of UHRF1 in breast cancer clinical samples detected by semi-quantitative RT-PCR. This figure is cited from our article (Unoki et al., 2004). 


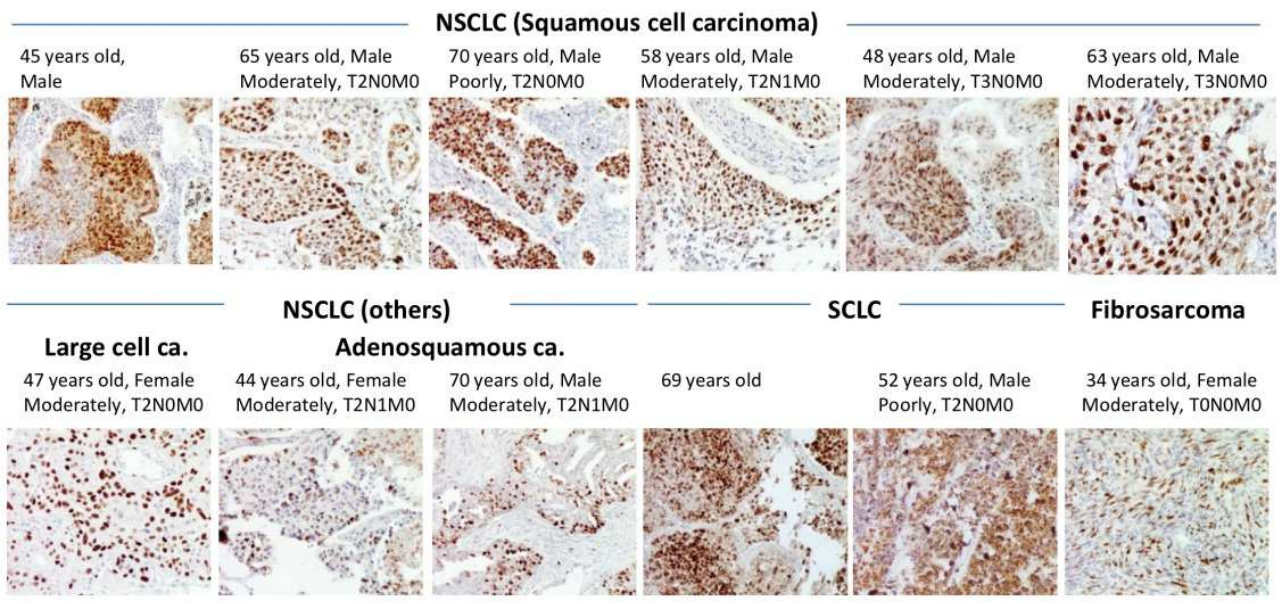

Fig. 4. Expression of UHRF1 in lung cancer clinical samples detected by immunohistochemistry. Representative data of UHRF1 staining in small cell lung carcinoma (SCLC), fibrosarcoma, and non-adenocarcinoma (ADC) histological types of non-small-cell lung carcinoma including squamous cell carcinoma (SCC), large cell carcinoma, and adenosquamous carcinoma ( $x$ 200). This figure is cited from our article (Unoki et al., 2010).

\subsection{UHRF1 is overexpressed in bladder cancer}

Considering these features of UHRF1, we thought that UHRF1 could be also important for bladder carcinogenesis, and examined expression of UHRF1 in bladder cancer specimens obtained from 124 UK cases (Table 1) and 36 Japanese cases (Unoki et al., 2009b). As a result, we found that UHRF1 was significantly overexpressed in bladder cancers at the mRNA and protein level (Fig. 5 and Fig. 6).

Because overexpression of UHRF1 in the cancer was detected both in UK cases and also in Japanese cases, the overexpression of UHRF1 could be common worldwide. Recently, another group showed that UHRF1 is also overexpressed in superficial, non-muscleinvasive bladder cancer of Chinese cases (Yang et al., 2011). Their result supports our observation. We also examined correlation between expression of UHRF1, p53, and p21/WAF1, and observed accumulation of stabilized p53 protein, which is probably mutated, in cancer tissues at grade II-III. However, we did not observe any accumulation of p53 in cancer tissues at grade I, although overexpression of UHRF1 was observed in this grade (Fig. 7). There was no relationship between expression levels of UHRF1 and $p 21$ mRNA. Therefore, UHRF1 seems to be superior to p53 as a potential diagnostic marker of bladder cancer. This result is concordant with the fact that p53 is mutated only in 10-30 \% of bladder cancer cases (Berggren et al., 2001; Lorenzo Romero et al., 2004). 


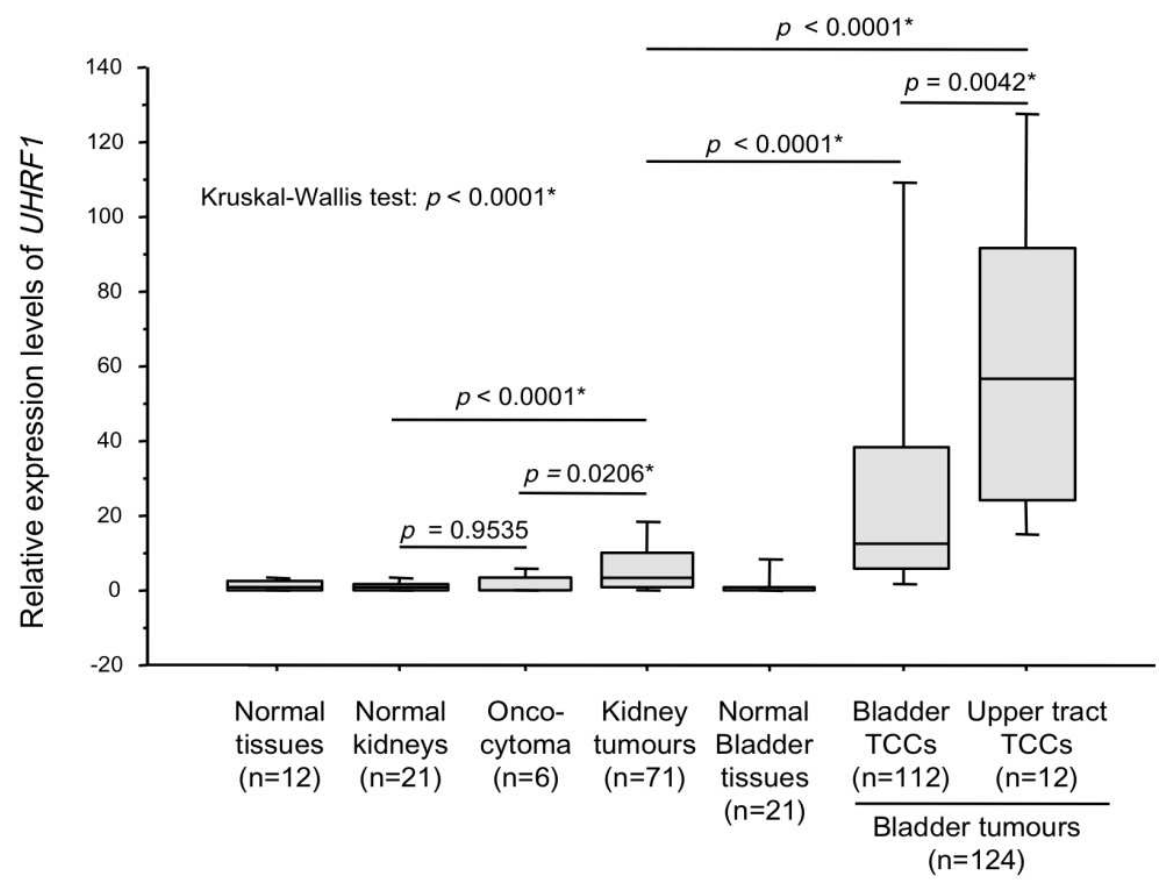

Fig. 5. Expression levels of UHRF1 mRNA in urinary system tumours and normal tissues detected by TaqMan qRT-PCR. Expression of UHRF1 in 12 different normal tissues, 21 normal kidneys, 6 oncocytomas, 71 kidney tumours, 21 normal bladders, and 124 bladder tumours, including 112 bladder located transitional cell carcinomas (TCCs) and 12 TCCs occurred in upper tract, were compared. Expression of UHRF1 differed among the seven groups ( $p<0.0001$, Kruskal-Wallis' test). Expression of UHRF1 in the kidney cancers was higher than that in the normal kidneys and also in the oncocytomas significantly $(p<0.0001$, and $p=0.0206$, respectively, Mann-Whiteney's U-test), but expression levels of UHRF1 in the bladder cancers were much higher than those in the kidney cancers $(p<0.0001$, MannWhiteney's U-test). Among the bladder cancers, expression of UHRF1 was significantly high in upper tract TCCs $(n=12)$ compared with the bladder-origin bladder tumours $(n=112)$ (Mann-Whiteney's U-test; $p=0.0042$ ). $\beta 2$-microgloblin was used for normalization. Asterisk indicates statistically significant $p$-values. This figure is cited from our article (Unoki et al., 2009b). 


\begin{tabular}{|c|c|c|c|}
\hline Characteristics & an $(\%)$ & Characteristics & n $(\%)$ \\
\hline Total numbers of patients & 124 & Sex & \\
\hline Anatomic site & & Male & $75(72 \%)$ \\
\hline Bladder & $\begin{array}{l}112 \\
(90 \%)\end{array}$ & Female & $29(28 \%)$ \\
\hline Upper tract & $12(10 \%)$ & Numbers of tumours & \\
\hline Type & & $<4$ & $53(85 \%)$ \\
\hline TCC & $\begin{array}{l}122 \\
(>99 \%)\end{array}$ & $>4$ & $9(15 \%)$ \\
\hline Others & $1(<1 \%)$ & Tumour size & \\
\hline Invasiveness & & $<5$ & $38(66 \%)$ \\
\hline Superficial & $71(63 \%)$ & $>5$ & $20(34 \%)$ \\
\hline Invasive & $41(37 \%)$ & Growth pattern & \\
\hline T-category & & ${ }^{\mathrm{c} C I S}$ & $1(2 \%)$ \\
\hline Ta & $40(35 \%)$ & Papillary & $32(52 \%)$ \\
\hline $\mathrm{T} 1$ & $32(28 \%)$ & Solid & $19(31 \%)$ \\
\hline $\mathrm{T} 2$ & $24(21 \%)$ & Solid/Papillary & $9(15 \%)$ \\
\hline $\mathrm{T} 3$ & $14(12 \%)$ & Recurrence & \\
\hline $\mathrm{T} 4$ & $4(4 \%)$ & No & $19(29 \%)$ \\
\hline WHO grading & & Yes & $46(71 \%)$ \\
\hline Grade 1 & $9(8 \%)$ & 5-years survival & \\
\hline Grade 2 & $59(51 \%)$ & Alive & $46(49 \%)$ \\
\hline Grade 3 & $47(41 \%)$ & Dead & $48(51 \%)$ \\
\hline Risk after bTURBT & & Smoking & \\
\hline Low & $7(13 \%)$ & Non-smoker & $22(35 \%)$ \\
\hline Intermediate & $26(46 \%)$ & Smoker & $40(65 \%)$ \\
\hline High & $23(41 \%)$ & & \\
\hline
\end{tabular}

aTotal numbers of the patients are not always 124, because not all patients have all the clinical information; bTURBT, transurethral resection of the bladder tumour; ${ }^{\mathrm{c} C I S}$, carcinoma in situ.

Table 1. Base line characteristics of bladder cancer patients used for our analyses (Unoki et al., 2009b).

We also examined expression of UHRF1 in kidney cancer, another urinary system tumour, together with the bladder cancer by immunohistochemistry. Although overexpression of UHRF1 is significant at mRNA level (Fig. 5), expression of UHRF1 in kidney cancer was not detected at protein level (Fig. 8A). Therefore, immunohistochemical staining of UHRF1 in the cancer seems not to be useful. However, overexpression of UHRF1 at the mRNA level was associated with several characteristics of kidney cancer patients including 5-year survival rates, pathological staging and histological grade (Fig. 8B-D). Thus, detection of 
UHRF1 mRNA overexpression in surgical specimen might be useful as a prognosis tool in kidney cancer.

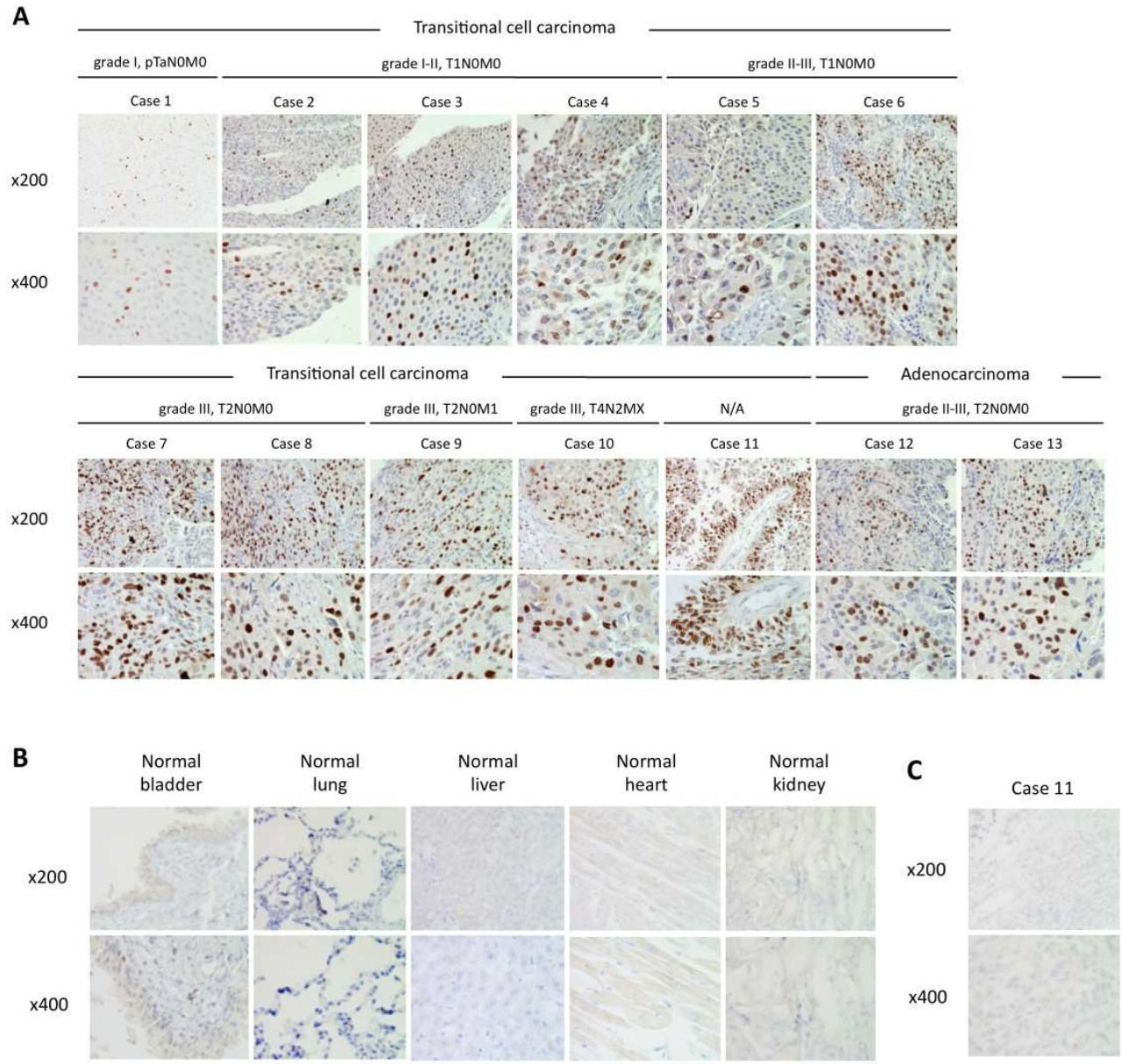

Fig. 6. Immunohistochemical staining of UHRF1 in 13 bladder tumour cases. A.

Expression of UHRF1 in 11 transitional cell carcinomas and two adenocarcinomas with the different stage and grade. High expression of UHRF1 was detected only in nucleus of cancer cells, not in stromal cells. B. Expression of UHRF1 in normal tissues including bladder, lung, liver, heart, and kidney. No expression was observed in these normal tissues. Original magnifications, $x 200$ (top), and x 400 (bottom). C. Representative images of normal IgG staining as a negative control (Case 11 used for Fig. 6A). Original magnifications, $x 200$ (top), and $\times 400$ (bottom). This figure is cited from our article (Unoki et al., 2009b). 


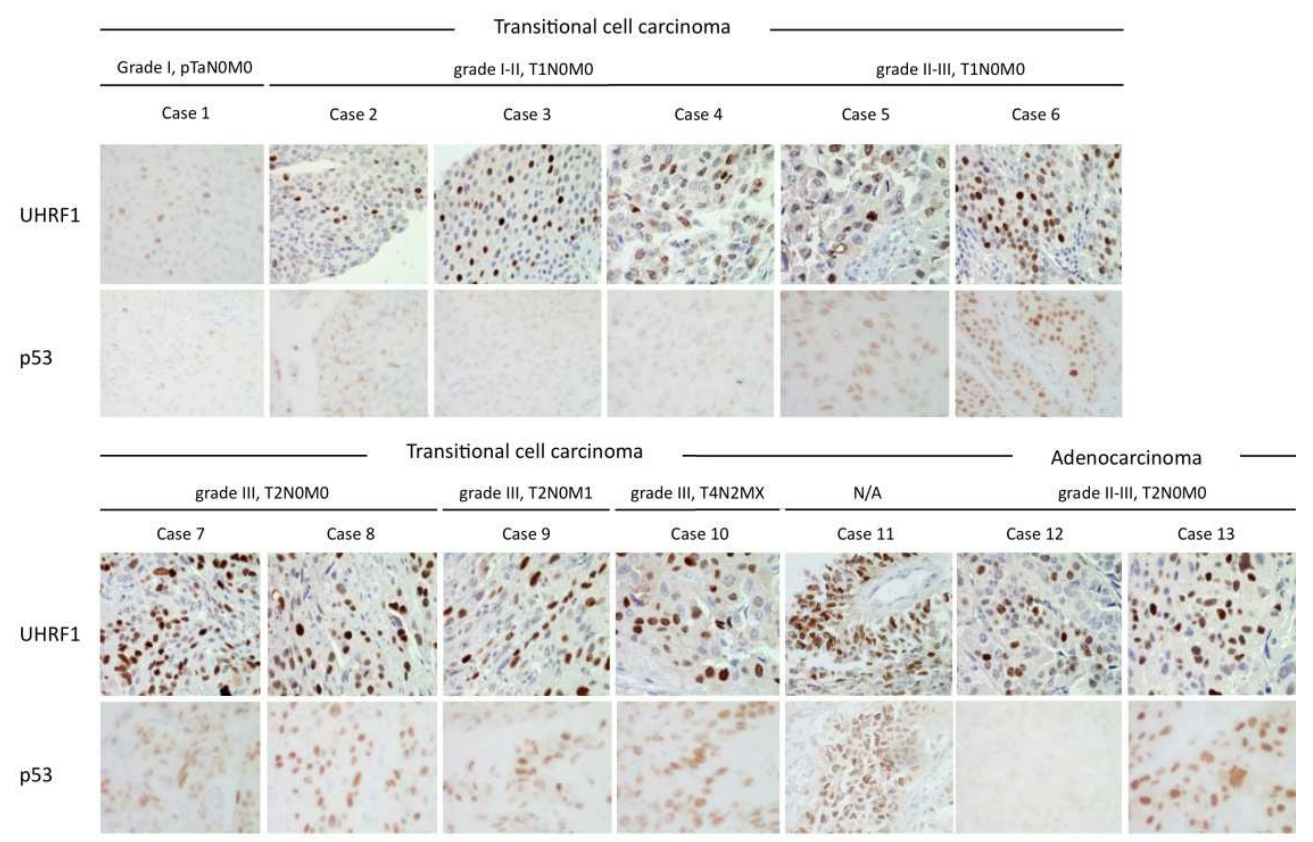

Fig. 7. Expression of p53 and UHRF1 in bladder cancers detected by immunohistochemistry. This figure is cited from our article (Unoki et al., 2009b). 


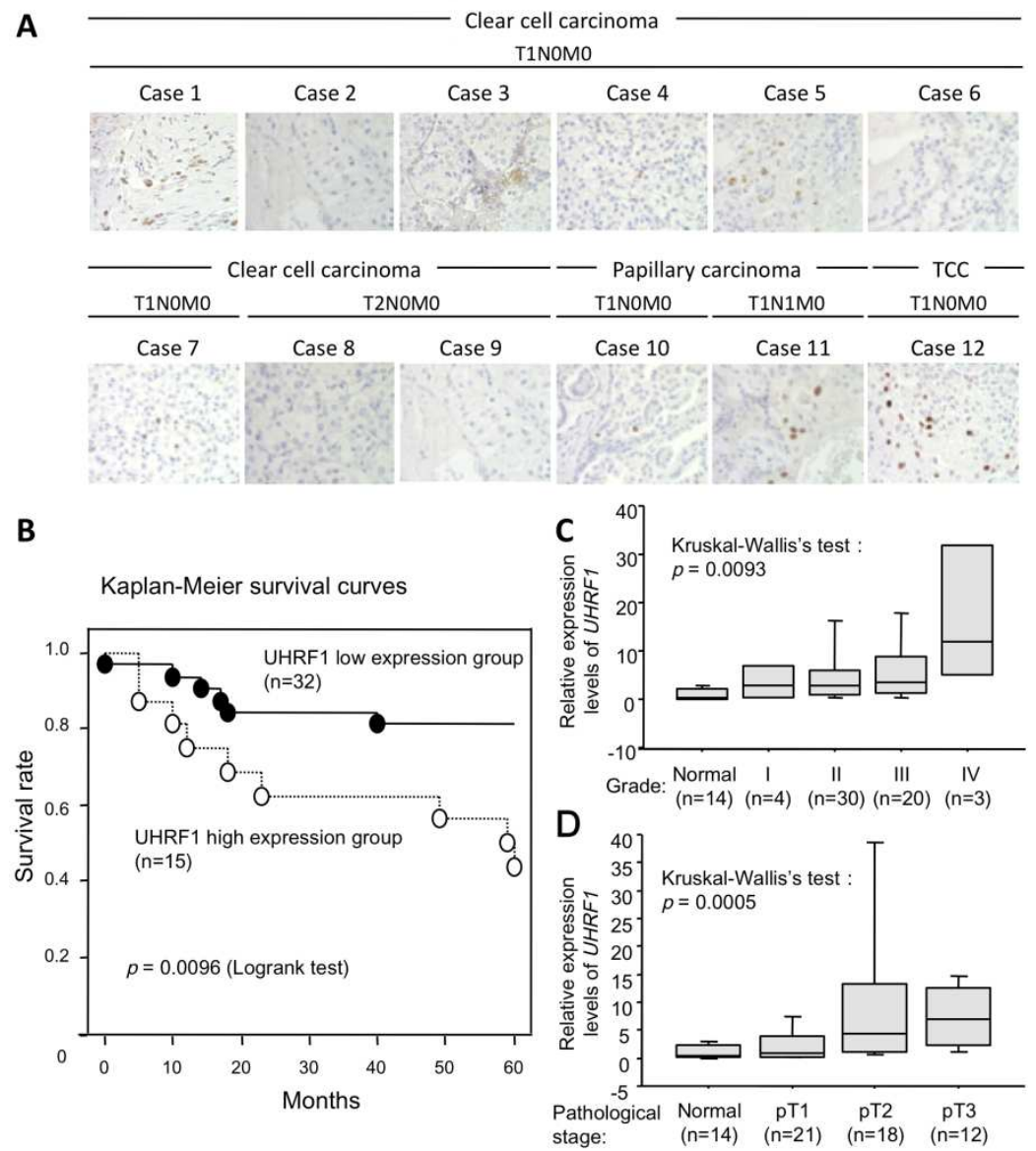

Fig. 8. Expression of UHRF1 in kidney cancer. A. UHRF1 expression in kidney cancers examined by immunohistochemistry. Magnification level is $x 400$. B. Expression levels of UHRF1 correlate with 5-years' survival rate of kidney tumours detected by TaqMan qRTPCR. Patients were categorized into two groups by expression levels of UHRF1. The UHRF1 high expression group is a group, which expresses UHRF1 eight or more $(\geq 8)$ and the low expression group is a group, which expresses UHRF1 less than eight fold $(<8)$ compared with average of UHRF1 expression level in normal kidney from 21 individuals as 1.0. In the result of Kaplan-Meier survival analysis, the UHRF1 high expression group showed significantly poor survival rate compared with the UHRF1 low expression group $(p=0.0096$ : Logrank test). $\beta 2$-microgloblin was used for normalization. C. Expression levels of UHRF1 correlated with histological grade of kidney tumours detected by TaqMan qRT-PCR. Patients were categorized into four groups by histological grade (I to IV). High expression of UHRF1 correlated with advanced grade ( $p=0.0093$ : Kruskal-Wallis's test). $\beta 2$-microgloblin was used for normalization. D. Expression levels of UHRF1 correlated with pathological staging and histological grade of renal cancers detected by TaqMan qRT-PCR. Patients were categorized into three groups with pathological stages, pT1 to pT3. High expression of 
UHRF1 correlated with advanced stage ( $p=0.0005$ : Kruskal-Wallis's test). $\beta 2$-microgloblin was used for normalization. This figure is cited from our article (Unoki et al., 2009b).

\subsection{Expression level of UHRF1 correlates with malignancy of bladder cancer}

We examined correlations between UHRF1 expression in bladder cancer and various clinical features of the patients (Table 1). Among these features, the expression of UHRF1 correlated with the T-category and the WHO histological grading significantly (Fig. 9A and 9B). Expression level of UHRF1 in superficial bladder cancers (T-category: Ta and T1) and invasive bladder cancers (T-category classification: T2, T3 and T4) was both significantly higher than that in normal bladders. This result is concordant with data from the another group (Yang et al., 2011). In addition, expression of UHRF1 in invasive bladder cancers was higher than that in superficial cancers, when we compared the three groups, normal bladders, invasive bladder cancers (pTa, pT1), and superficial bladder cancers (pT2-4), by Kruskal-Wallis's test (Fig. 9A). In addition, expression level of UHRF1 in cancers with grade-II and -III was up-regulated compared with that in normal bladders (Fig. 9B). Therefore, up-regulation level of UHRF1 reflects progression level of bladder cancer.

A

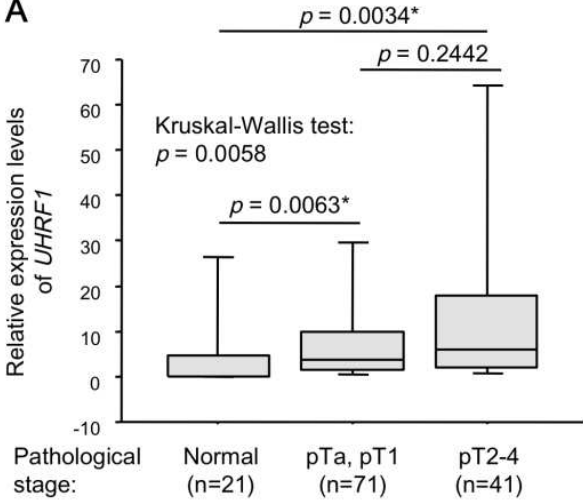

B

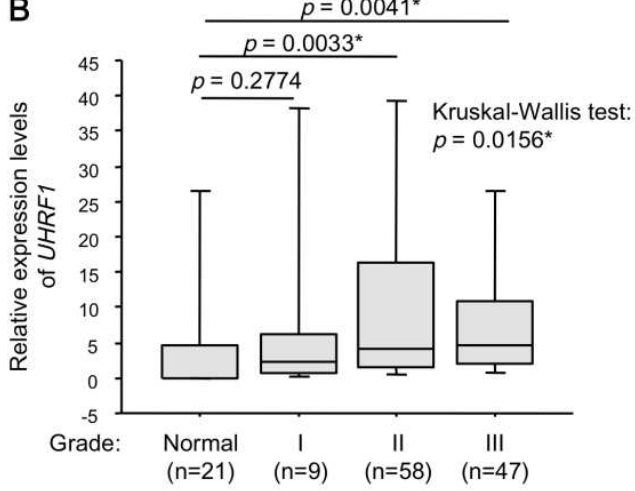

Fig. 9. Expression of UHRF1 correlated with the stage, and grade. A. Expression of UHRF1 in 21 normal bladders, 71 superficial bladder tumours (T-category is pTa and pT1), and 41 invasive bladder tumours (T-category is pT2, pT3, and pT4) detected by TaqMan qRT-PCR. Expression levels of UHRF1 in superficial bladder tumours and in invasive tumours were significantly higher compared with those in normal bladders by Mann-Whiteney's U-test $(p=0.0063$ and $p=0.0034$, respectively). Although its expression in superficial tumours and invasive tumours did not differ ( $p=0.2442$, Mann-Whiteney's U-test), it differed among the three different groups ( $p=0.0058$, Kruskal-Wallis' test). $\beta 2$-microgloblin was used for normalization. B. Expression of UHRF1 differed among four groups with the different grade ( $p=0.0156$, Kruskal-Wallis' test) detected by TaqMan qRT-PCR. Expression of UHRF1 in grade II, and III tumour was higher than that in the normal bladders $(p=0.0033$ and $p=0.0041)$. $\beta 2$-microgloblin was used for normalization.

In our result, expression of UHRF1 was not associated with difference of gender, numbers of tumour, tumour size, growth pattern (papillary or solid), incidence of recurrence, survival status after five years from surgery, and smoking history (Fig. 10), although the another 
group showed an association between UHRF1 expression levels and tumour recurrence in superficial bladder cancer of Chinese cases (Yang et al., 2011). Therefore, UHRF1 could be a molecular marker for predicting the recurrence of superficial bladder cancers in some ethnic groups.

A

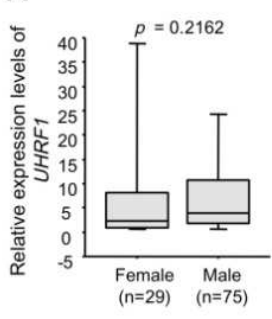

D

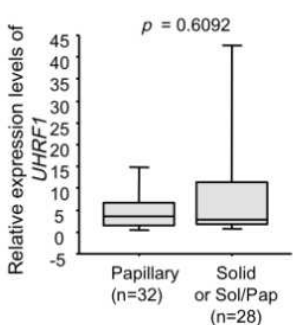

B

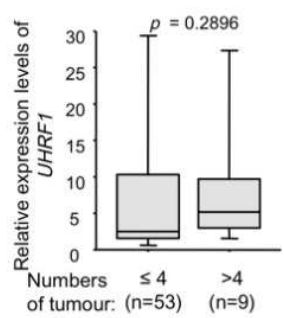

E

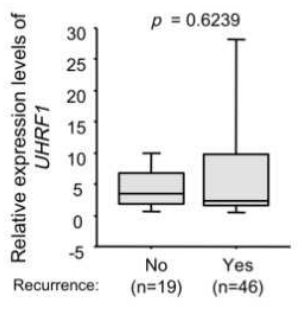

C

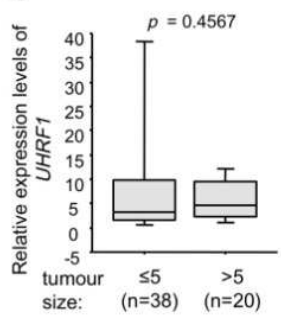

$\mathbf{F}$

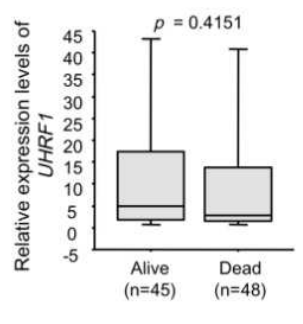

G

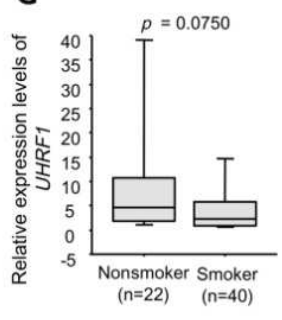

Fig. 10. Expression of UHRF1 detected by TaqMan qRT-PCR and many characteristics of patients were compared by Mann-Whiteney's U-test. A. Expression levels of UHRF1 in female patients $(n=29)$ and male patients $(n=75)$. Gender was not associated with expression levels of UHRF1 ( $\mathrm{p}=0.2162$ ). B. Expression levels of UHRF1 in patients with tumours four and less $(n=53)$ and more than four $(n=9)$ were not different $(p=0.2896)$. C. Expression levels of UHRF1 in patients with $\leq 5 \mathrm{~cm}$ tumours $(n=38)$ and with $>5 \mathrm{~cm}$ tumours $(n=20)$ were not different $(\mathrm{p}=0.4567)$. D. Expression levels of UHRF1 in patients with papillary type tumours $(n=32)$ and with solid or solid/papillary tumours $(n=28)$ were not different $(p=0.4567)$. E. Expression levels of UHRF1 in patients who did not have a recurrence $(n=19)$ and have a recurrence $(\mathrm{n}=46)$ were not different $(\mathrm{p}=0.6239)$. F. Expression levels of $U H R F 1$ in patients who survived 5 years after surgery $(n=45)$ and died within 5 years $(n=48)$ were not different $(p=0.4151)$. $G$.

Expression levels of UHRF1 in non-smoker patients $(\mathrm{n}=22)$ and smoker patients including 4 exsmokers $(n=40)$ was not different $(\mathrm{p}=0.0750)$. $\beta 2$-microgloblin was used for normalization.

\subsection{Expression UHRF1 can be used for predicting recurrence risk after TURBT}

Over $75 \%$ bladder cancer patients have one or more superficial bladder cancers, and two thirds of them will develop recurrent disease (Lutzeyer et al., 1982), with 10-20\% progressing to an invasive phenotype (Torti \& Lum, 1984). The outcome of patients with invasive tumours remains still poor, with distant metastasis occurring in over $50 \%$ within 2 years and an average 5-year survival of only 50\% (Raghavan et al., 1990). Currently, superficial bladder cancers are resected by a procedure called TURBT (TransUrethral 
Resection of Bladder Tumour), and patients are treated differently based on estimated recurrence risk after TURBT. Thus, diagnosis of bladder cancer at non-advanced stage and also precise estimation of the risk after the TURBT, are very important for prognosis of patients. Currently, the risk after the surgery is estimated by a scoring system and risk tables developed by European Organization for Research and Treatment of Cancer (EORTC). The EORTC scoring system was developed based on the six most significant clinical and pathological factors, which are tumour stage, tumour grade, numbers of tumour, tumour size, prior recurrence rate, and presence of carcinoma in situ (CIS). Bladder cancer patients with pTaG1 tumours (50\% of all patients) are at very low risk, and those with CIS or with pT1G3 tumours are at the highest risk (15\% of all patients). Intermediate risk patients are those with pTa/pT1 G1/G2 disease who develop multiple recurrent cancers (35\% of all patients). Our TaqMan qRT-PCR result showed that high expression of UHRF1 was associated with high risk after TURBT (Fig. 11), probably because reflecting the association between high expression of UHRF1 and stage, and/or grade (Fig. 9A and 9B). Based on these results, detection of UHRF1 in tissue samples after TURBT will be a prognostic marker of future recurrence and may help to determine the risk together with the current prognostic factors.

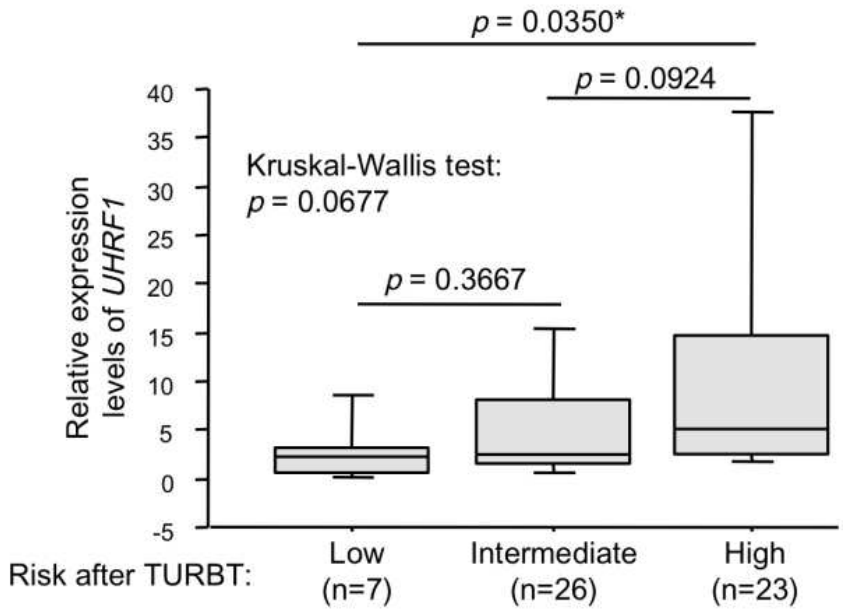

Fig. 11. Expression of $U H R F 1$ correlated with the recurrence risk after TURBT. Significant high expression of UHRF1 in the high risk group after TURBT $(n=23)$ was observed compared with that in the low risk group $(n=7)$ by Mann-Whiteney's U-test $(p=0.0350)$. Asterisk indicates statistically significant $p$-values. $\beta 2$-microgloblin was used for normalization. This figure is cited from our article (Unoki et al., 2009b).

\subsection{UHRF1 is a possible marker of bladder cancers and upper tract TCCs}

Because UHRF1 was significantly overexpressed in bladder cancers and upper tract TCCs (Fig. 5), UHRF1 might be a useful diagnostic marker especially for upper tract TCCs. Upper tract TCCs are often very malignant when it is diagnosed, partially because it is relatively difficult to find at an early stage. If the cancer is found at an early stage, the 
prognosis of patients is improved. The development of a sensitive urine based detection marker is still being sought. Examination of voided urine or bladder barbotage for exfoliated cancer cells is useful for diagnosis of urothelial tumours anywhere in the urinary tract, from the calyx, through the ureters, into bladder and urethra. However, cytological interpretation can be problematic; low cellular yields, atypia, degenerative changes, urinary tract infections, stones and intravesical instillations hamper a correct diagnosis. Because the current two biomarker tests in clinical use, NMP-22 detection and BTA stat/BTA TRAK assay, can be hampered by existence of bleeding, inflammation, recent genitourinary tumours, and bladder stone (Dey, 2004), these markers have not improved the traditional cytology-based bladder cancer diagnosis largely. Thus, cytology is still the mainstay for diagnosing bladder cancer. Because the expression of UHRF1 in peripheral blood mononuclear cells (PBMCs) was under detection limit of qRT-PCR (Fig. 12), the presence of these cells in urine would not impede the diagnosis. Additionally, expression of UHRF1 was not detected in adjacent normal bladder tissues by immunohistochemistry (Fig. 6A and 6B). Thus, contamination of these stromal cells also would not disturb the diagnosis, either. Therefore, an immunohistochemistry or EnzymeLinked ImmunoSorbent Assay (ELISA)-based UHRF1 detection in urine sediment can be a sensitive and cancer-specific diagnostic method, and may greatly improve the current diagnosis based on cytology.

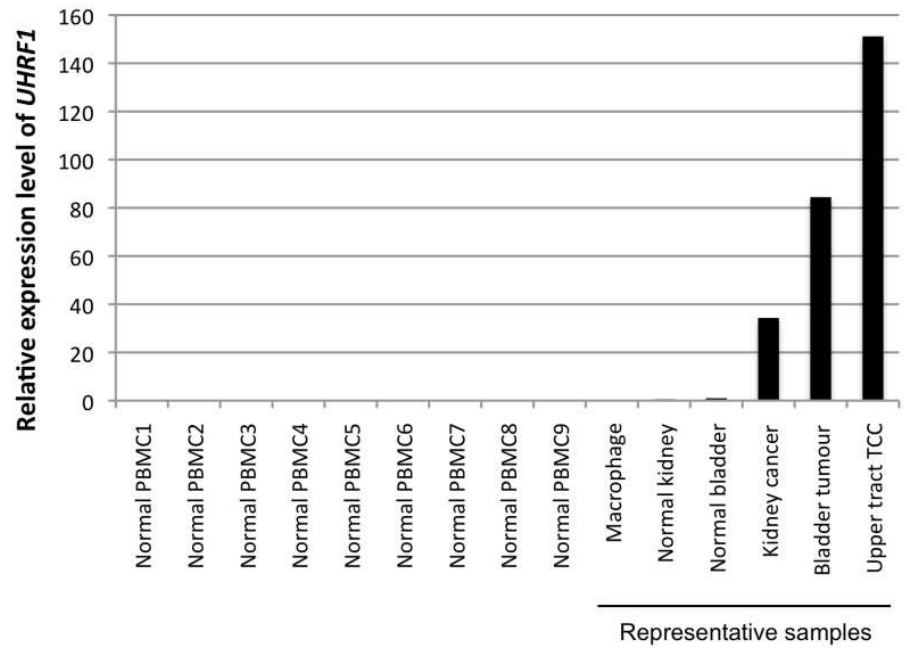

\begin{tabular}{lc} 
& \multicolumn{1}{c}{ Fold } \\
\hline Normal PBMC1 & 0.06 \\
Normal PBMC2 & 0.00 \\
Normal PBMC3 & 0.00 \\
Normal PBMC4 & 0.01 \\
Normal PBMC5 & 0.01 \\
Normal PBMC6 & 0.01 \\
Normal PBMC7 & 0.01 \\
Normal PBMC8 & 0.01 \\
Normal PBMC9 & 0.00 \\
Macrophage & 0.00 \\
Normal kidney & 0.53 \\
Normal bladder & 1.00 \\
Kidney cancer & 34.30 \\
Bladder tumour & 84.45 \\
Upper tract TCC & 151.17 \\
\hline
\end{tabular}

Fig. 12. Relative expression levels of UHRF1 in peripheral blood mononuclear cells (PBMCs) were examined by TaqMan qRT-PCR. Almost no expression of UHRF1 was detected in PBMCs. 


\section{Conclusion}

Although UHRF1 expression in muscle invasive cancer was greater than in non-invasive (pTa) or superficially invasive (pT1) cancers, UHRF1 could still be detected by immunohistochemistry in the early stage bladder cancers. In addition, overexpression of UHRF1 was associated with increased risk of progression after TURBT. Therefore, our result indicates that detection of UHRF1 may be a useful marker for early stage bladder cancers, and also for estimation of risk after TURBT, although it should be tested in larger series to determine if it can improve current strategies for diagnosis and prognosis of bladder cancer.

\section{Acknowledgement}

I thank Professor Yusuke Nakamura for his continuous support of my research, Dr. Ryuji Hamamoto, Professor John D. Kelly, Professor David E. Neal, and Professor Sir Bruce A. J. Ponder for providing us UK bladder cancer specimens and for helpful discussion, Professor Tomoaki Fujioka for providing us Japanese bladder cancer specimens, and Drs. Ryo Takata, Hitoshi Zembutsu, and Yoichiro Kato for very useful advice and discussion.

\section{References}

Abbady, A. Q.; Bronner, C.; Bathami, K.; Muller, C. D.; Jeanblanc, M.; Mathieu, E.; Klein, J. P.; Candolfi, E. \& Mousli, M. (2005). TCR pathway involves ICBP90 gene downregulation via E2F binding sites. Biochem Pharmacol, Vol.70, No.4, (Aug 2005), pp.570-579, ISSN 0006-2952

Achour, M.; Jacq, X.; Ronde, P.; Alhosin, M.; Charlot, C.; Chataigneau, T.; Jeanblanc, M.; Macaluso, M.; Giordano, A.; Hughes, A. D.; Schini-Kerth, V. B. \& Bronner, C. (2008). The interaction of the SRA domain of ICBP90 with a novel domain of DNMT1 is involved in the regulation of VEGF gene expression. Oncogene, Vol.27, No.15, (Apr 2008), pp.2187-2197, ISSN 1476-5594

Achour, M.; Fuhrmann, G.; Alhosin, M.; Ronde, P.; Chataigneau, T.; Mousli, M.; SchiniKerth, V. B. \& Bronner, C. (2009). UHRF1 recruits the histone acetyltransferase Tip60 and controls its expression and activity. Biochem Biophys Res Commun, Vol.390, No.3, (Oct 2009), pp.523-528, ISSN 1090-2104

Alhosin, M.; Abusnina, A.; Achour, M.; Sharif, T.; Muller, C.; Peluso, J.; Chataigneau, T.; Lugnier, C.; Schini-Kerth, V. B.; Bronner, C. \& Fuhrmann, G. (2010). Induction of apoptosis by thymoquinone in lymphoblastic leukemia Jurkat cells is mediated by a p73-dependent pathway which targets the epigenetic integrator UHRF1. Biochem Pharmacol, Vol.79, No.9, (May 2010), pp.1251-1260, ISSN 1873-2968

Arima, Y.; Hirota, T.; Bronner, C.; Mousli, M.; Fujiwara, T.; Niwa, S.; Ishikawa, H. \& Saya, H. (2004). Down-regulation of nuclear protein ICBP90 by p53/p21Cip1/WAF1-dependent DNA-damage checkpoint signals contributes to cell cycle arrest at G1/S transition. Genes Cells, Vol.9, No.2, (Feb 2004), pp.131-142, ISSN 1356-9597 
Arita, K.; Ariyoshi, M.; Tochio, H.; Nakamura, Y. \& Shirakawa, M. (2008). Recognition of hemi-methylated DNA by the SRA protein UHRF1 by a base-flipping mechanism. Nature, Vol.455, No.7214, (Oct 2008), pp.818-821, ISSN 1476-4687

Avvakumov, G. V.; Walker, J. R.; Xue, S.; Li, Y.; Duan, S.; Bronner, C.; Arrowsmith, C. H. \& Dhe-Paganon, S. (2008). Structural basis for recognition of hemi-methylated DNA by the SRA domain of human UHRF1. Nature, Vol.455, No.7214, (Oct 2008), pp.822825, ISSN 1476-4687

Berggren, P.; Steineck, G.; Adolfsson, J.; Hansson, J.; Jansson, O.; Larsson, P.; Sandstedt, B.; Wijkstrom, H. \& Hemminki, K. (2001). p53 mutations in urinary bladder cancer. Br J Cancer, Vol.84, No.11, (Jun 2001), pp.1505-1511, ISSN 0007-0920

Bronner, C.; Achour, M.; Arima, Y.; Chataigneau, T.; Saya, H. \& Schini-Kerth, V. B. (2007). The UHRF family: oncogenes that are drugable targets for cancer therapy in the near future? Pharmacol Ther, Vol.115, No.3, (Sep 2007), pp.419-434, ISSN 0163-7258

Crnogorac-Jurcevic, T.; Gangeswaran, R.; Bhakta, V.; Capurso, G.; Lattimore, S.; Akada, M.; Sunamura, M.; Prime, W.; Campbell, F.; Brentnall, T. A.; Costello, E.; Neoptolemos, J. \& Lemoine, N. R. (2005). Proteomic analysis of chronic pancreatitis and pancreatic adenocarcinoma. Gastroenterology, Vol.129, No.5, (Nov 2005), pp.14541463, ISSN 0016-5085

Dey, P. (2004). Urinary markers of bladder carcinoma. Clin Chim Acta, Vol.340, No.1-2, (Feb 2004), pp.57-65, ISSN 0009-8981

Hashimoto, H.; Horton, J. R.; Zhang, X.; Bostick, M.; Jacobsen, S. E. \& Cheng, X. (2008). The SRA domain of UHRF1 flips 5-methylcytosine out of the DNA helix. Nature, Vol.455, No.7214, (Oct 2008), pp.826-829, ISSN 1476-4687

Hashimoto, H.; Horton, J. R.; Zhang, X. \& Cheng, X. (2009). UHRF1, a modular multidomain protein, regulates replication-coupled crosstalk between DNA methylation and histone modifications. Epigenetics, Vol.4, No.1, (Jan 2009), pp.8-14, ISSN 15592308

Hopfner, R.; Mousli, M.; Jeltsch, J. M.; Voulgaris, A.; Lutz, Y.; Marin, C.; Bellocq, J. P.; Oudet, P. \& Bronner, C. (2000). ICBP90, a novel human CCAAT binding protein, involved in the regulation of topoisomerase IIalpha expression. Cancer Res, Vol.60, No.1, (Jan 2000), pp.121-128, ISSN 0008-5472

Hussain, S. P. \& Harris, C. C. (2000). Molecular epidemiology and carcinogenesis: endogenous and exogenous carcinogens. Mutat Res, Vol.462, No.2-3, (Apr 2000), pp.311-322, ISSN 0027-5107

Jeanblanc, M.; Mousli, M.; Hopfner, R.; Bathami, K.; Martinet, N.; Abbady, A. Q.; Siffert, J. C.; Mathieu, E.; Muller, C. D. \& Bronner, C. (2005). The retinoblastoma gene and its product are targeted by ICBP90: a key mechanism in the G1/S transition during the cell cycle. Oncogene, Vol.24, No.49, (Nov 2005), pp.7337-7345, ISSN 0950-9232

Jemal, A.; Bray, F.; Center, M. M.; Ferlay, J.; Ward, E. \& Forman, D. (2011). Global cancer statistics. CA Cancer J Clin, (Feb 2011), ISSN 1542-4863

Jenkins, Y.; Markovtsov, V.; Lang, W.; Sharma, P.; Pearsall, D.; Warner, J.; Franci, C.; Huang, B.; Huang, J.; Yam, G. C.; Vistan, J. P.; Pali, E.; Vialard, J.; Janicot, M.; Lorens, J. B.; Payan, D. G. \& Hitoshi, Y. (2005). Critical role of the ubiquitin ligase activity of 
UHRF1, a nuclear RING finger protein, in tumor cell growth. Mol Biol Cell, Vol.16, No.12, (Dec 2005), pp.5621-5629, ISSN 1059-1524

Jin, W.; Liu, Y.; Xu, S. G.; Yin, W. J.; Li, J. J.; Yang, J. M. \& Shao, Z. M. (2010). UHRF1 inhibits MDR1 gene transcription and sensitizes breast cancer cells to anticancer drugs. Breast Cancer Res Treat, Vol.124, No.1, (Nov 2010), pp.39-48, ISSN 1573-7217

Karagianni, P.; Amazit, L.; Qin, J. \& Wong, J. (2008). ICBP90, a novel methyl K9 H3 binding protein linking protein ubiquitination with heterochromatin formation. Mol Cell Biol, Vol.28, No.2, (Jan 2008), pp.705-717, ISSN 1098-5549

Kim, J. K.; Esteve, P. O.; Jacobsen, S. E. \& Pradhan, S. (2009). UHRF1 binds G9a and participates in p21 transcriptional regulation in mammalian cells. Nucleic Acids Res, Vol.37, No.2, (Feb 2009), pp.493-505, ISSN 1362-4962

Li, X.; Meng, Q.; Rosen, E. M. \& Fan, S. (2011). UHRF1 confers radioresistance to human breast cancer cells. Int J Radiat Biol, Vol.87, No.3, (Mar 2011), pp.263-273, ISSN 13623095

Li, X. L.; Meng, Q. H. \& Fan, S. J. (2009). Adenovirus-mediated expression of UHRF1 reduces the radiosensitivity of cervical cancer HeLa cells to gamma-irradiation. Acta Pharmacol Sin, Vol.30, No.4, (Apr 2009), pp.458-466, ISSN 1745-7254

Lorenzato, M.; Caudroy, S.; Bronner, C.; Evrard, G.; Simon, M.; Durlach, A.; Birembaut, P. \& Clavel, C. (2005). Cell cycle and/or proliferation markers: what is the best method to discriminate cervical high-grade lesions? Hum Pathol, Vol.36, No.10, (Oct 2005), pp.1101-1107, ISSN 0046-8177

Lorenzo Romero, J. G.; Salinas Sanchez, A. S.; Gimenez Bachs, J. M.; Sanchez Sanchez, F.; Escribano Martinez, J.; Hernandez Millan, I. R.; Segura Martin, M. \& Virseda Rodriguez, J. A. (2004). p53 Gene mutations in superficial bladder cancer. Urol Int, Vol.73, No.3, (2004), pp.212-218, ISSN 0042-1138

Lutzeyer, W.; Rubben, H. \& Dahm, H. (1982). Prognostic parameters in superficial bladder cancer: an analysis of 315 cases. J Urol, Vol.127, No.2, (Feb 1982), pp.250-252, ISSN 0022-5347

Mousli, M.; Hopfner, R.; Abbady, A. Q.; Monte, D.; Jeanblanc, M.; Oudet, P.; Louis, B. \& Bronner, C. (2003). ICBP90 belongs to a new family of proteins with an expression that is deregulated in cancer cells. Br J Cancer, Vol.89, No.1, (Jul 2003), pp.120-127, ISSN 0007-0920

Muto, M.; Kanari, Y.; Kubo, E.; Takabe, T.; Kurihara, T.; Fujimori, A. \& Tatsumi, K. (2002). Targeted disruption of Np95 gene renders murine embryonic stem cells hypersensitive to DNA damaging agents and DNA replication blocks. J Biol Chem, Vol.277, No.37, (Sep 2002), pp.34549-34555, ISSN 0021-9258

Oba-Shinjo, S. M.; Bengtson, M. H.; Winnischofer, S. M.; Colin, C.; Vedoy, C. G.; de Mendonca, Z.; Marie, S. K. \& Sogayar, M. C. (2005). Identification of novel differentially expressed genes in human astrocytomas by cDNA representational difference analysis. Brain Res Mol Brain Res, Vol.140, No.1-2, (Oct 2005), pp.25-33, ISSN 0169-328X

Parkin, D. M.; Bray, F.; Ferlay, J. \& Pisani, P. (2005). Global Cancer Statistics, 2002. CA-Cancer J Clin, Vol.55, No.2, (Mar-Apr 2005), pp.74-108, ISSN 0007-9235 
Pita, J. M.; Banito, A.; Cavaco, B. M. \& Leite, V. (2009). Gene expression profiling associated with the progression to poorly differentiated thyroid carcinomas. Br J Cancer, Vol.101, No.10, (Nov 2009), pp.1782-1791, ISSN 1532-1827

Raghavan, D.; Shipley, W. U.; Garnick, M. B.; Russell, P. J. \& Richie, J. P. (1990). Biology and management of bladder cancer. N Engl J Med, Vol.322, No.16, (Apr 1990), pp.11291138, ISSN 0028-4793

Sharif, J.; Muto, M.; Takebayashi, S.; Suetake, I.; Iwamatsu, A.; Endo, T. A.; Shinga, J.; Mizutani-Koseki, Y.; Toyoda, T.; Okamura, K.; Tajima, S.; Mitsuya, K.; Okano, M. \& Koseki, H. (2007). The SRA protein Np95 mediates epigenetic inheritance by recruiting Dnmt1 to methylated DNA. Nature, Vol.450, No.7171, (Dec 2007), pp.908912, ISSN 1476-4687

Stein, J. P.; Lieskovsky, G.; Cote, R.; Groshen, S.; Feng, A. C.; Boyd, S.; Skinner, E.; Bochner, B.; Thangathurai, D.; Mikhail, M.; Raghavan, D. \& Skinner, D. G. (2001). Radical cystectomy in the treatment of invasive bladder cancer: long-term results in 1,054 patients. J Clin Oncol, Vol.19, No.3, (Feb 2001), pp.666-675, ISSN 0732-183X

Tien, A. L.; Senbanerjee, S.; Kulkarni, A.; Mudbhary, R.; Goudreau, B.; Ganesan, S.; Sadler, K. C. \& Ukomadu, C. (2011). UHRF1 depletion causes a G2/M arrest, activation of DNA damage response and apoptosis. Biochem J, Vol.435, No.1, (Apr 1 2011), pp.175-185, ISSN 1470-8728

Torti, F. M. \& Lum, B. L. (1984). The biology and treatment of superficial bladder cancer. J Clin Oncol, Vol.2, No.5, (May 1984), pp.505-531, ISSN 0732-183X

Unoki, M.; Nishidate, T. \& Nakamura, Y. (2004). ICBP90, an E2F-1 target, recruits HDAC1 and binds to methyl-CpG through its SRA domain. Oncogene, Vol.23, No.46, (Oct 2004), pp.7601-7610, ISSN 0950-9232

Unoki, M.; Brunet, J. \& Mousli, M. (2009a). Drug discovery targeting epigenetic codes: The great potential of UHRF1, which links DNA methylation and histone modifications, as a drug target in cancers and toxoplasmosis Biochem Pharmacol., Vol.78, No.10, (Nov 2009a), pp.1279-1288, ISSN 1873-2968

Unoki, M.; Kelly, J. D.; Neal, D. E.; Ponder, B. A. J.; Nakamura, Y. \& Hamamoto, R. (2009b). UHRF1 is a novel molecular marker for diagnosis and the prognosis of bladder cancer. Br J Cancer, Vol.101, No.1, ( Jul 2009b), pp.98-105, ISSN 1532-1827

Unoki, M.; Daigo, Y.; Koinuma, J.; Tsuchiya, E.; Hamamoto, R. \& Nakamura, Y. (2010). UHRF1 is a novel diagnostic marker of lung cancer. Br J Cancer, Vol.103, No.2, (Jul 2010), pp.217-222, ISSN 1532-1827

Unoki, M. (2011). Current and potential anticancer drugs targeting members of the UHRF1 complex including epigenetic modifiers. Recent Pat Anticancer Drug Discov, Vol.6, No.1, (Jan 2011), pp.116-130, ISSN 1574-8928

van Rhijn, B. W.; van der Poel, H. G. \& van der Kwast, T. H. (2005). Urine markers for bladder cancer surveillance: a systematic review. Eur Urol, Vol.47, No.6, (Jun 2005), pp.736-748, ISSN 0302-2838

Yan, F.; Tan, X. Y.; Geng, Y.; Ju, H. X.; Gao, Y. F. \& Zhu, M. C. (2011). Inhibition Effect of siRNA-Downregulated UHRF1 on Breast Cancer Growth. Cancer Biother Radiopharm, Vol.26, No.2, (Apr 2011), pp.183-189, ISSN 1557-8852 
Yang, G. L.; Zhang, L. H.; Bo, J. J.; Chen, H. G.; Cao, M.; Liu, D. M. \& Huang, Y. R. (2011). UHRF1 is associated with tumor recurrence in non-muscle-invasive bladder cancer. Med Oncol, (May 25 2011), ISSN 1559-131X 


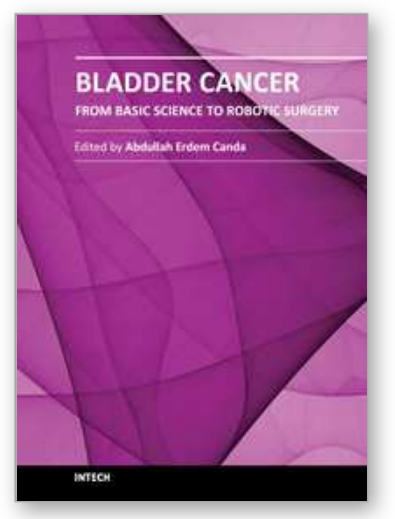

\author{
Bladder Cancer - From Basic Science to Robotic Surgery \\ Edited by Dr. Abdullah Canda
}

ISBN 978-953-307-839-7

Hard cover, 460 pages

Publisher InTech

Published online 01, February, 2012

Published in print edition February, 2012

This book is an invaluable source of knowledge on bladder cancer biology, epidemiology, biomarkers, prognostic factors, and clinical presentation and diagnosis. It is also rich with plenty of up-to-date information, in a well-organized and easy to use format, focusing on the treatment of bladder cancer including surgery, chemotherapy, radiation therapy, immunotherapy, and vaccine therapy. These chapters, written by the experts in their fields, include many interesting, demonstrative and colorful pictures, figures, illustrations and tables. Due to its practicality, this book is recommended reading to anyone interested in bladder cancer.

\title{
How to reference
}

In order to correctly reference this scholarly work, feel free to copy and paste the following:

Motoko Unoki (2012). UHRF1 is a Potential Molecular Marker for Diagnosis and Prognosis of Bladder Cancer, Bladder Cancer - From Basic Science to Robotic Surgery, Dr. Abdullah Canda (Ed.), ISBN: 978-953-307-8397, InTech, Available from: http://www.intechopen.com/books/bladder-cancer-from-basic-science-to-roboticsurgery/uhrf1-is-a-potential-molecular-marker-for-diagnosis-and-prognosis-of-bladder-cancer

\section{INTECH}

open science | open minds

\section{InTech Europe}

University Campus STeP Ri

Slavka Krautzeka 83/A

51000 Rijeka, Croatia

Phone: +385 (51) 770447

Fax: +385 (51) 686166

www.intechopen.com

\section{InTech China}

Unit 405, Office Block, Hotel Equatorial Shanghai

No.65, Yan An Road (West), Shanghai, 200040, China

中国上海市延安西路65号上海国际贵都大饭店办公楼 405 单元

Phone: +86-21-62489820

Fax: +86-21-62489821 
(C) 2012 The Author(s). Licensee IntechOpen. This is an open access article distributed under the terms of the Creative Commons Attribution 3.0 License, which permits unrestricted use, distribution, and reproduction in any medium, provided the original work is properly cited. 